\title{
ARTICLE
}

\section{Neutron Flux Measurements in ITER-TBM Simulating Assemblies by means of Multi-Foil Activation Method}

\author{
Kentaro OCHIAI*, Yosuke TATEBE, Keitaro KONDO, Seiki OHNISHI, Satoshi SATO, \\ Kosuke TAKAKURA, and Chikara KONNO \\ Japan Atomic Energy Agency, Tokai, Naka, Ibaraki 319-1195, Japan
}

\begin{abstract}
We measured neutron spectra in beryllium and an ITER-TBM simulating assemblies by means of a Multi-Foil Activation Method (MFAM) at the FNS facility of JAEA to confirm applicability of MFAM. An unfolding code, NEUPAC, was used to determine neutron flux spectra. Initial guessed neutron spectra were calculated with the Monte Carlo code MCNP4C and a nuclear data library FENDL-2.1. JENDL Dosimetry File 99 was adopted as response data for reaction rates. We deduced neutron flux spectra in the simulated assemblies with the MFAM. From the experiments, it was found out that MFAM gave appropriate results, which indicated that MFAM was a prospect to the application of neutron spectrum measurement in ITER-TBM. However, it was also pointed out that some improvements for measurement of slow neutron below $10 \mathrm{eV}$ were necessary.
\end{abstract}

KEYWORDS: fusion neutronics, test blanket module, ITER, neutron spectrum, multi-foil activation meth od

\section{Introduction ${ }^{1}$}

Examinations of nuclear performances with Test Blanket Modules (TBM) are arranged in the International Thermonuclear Experimental Reactor (ITER). The TBM proposed by Japan Atomic Energy Agency (JAEA) ${ }^{1)}$ is a kind of water cooled solid breeder with beryllium and lithium ceramics. Basically, the nuclear performances of ITER-TBM can be calculated with a neutron transport code and a nuclear data library. In order to validate the calculation, it is essential to perform some nuclear measurements in the ITER-TBM.

For the measurement, the multi-foil activation method (MFAM) is considered to be one of the most prospective candidates for the neutron spectrum measurement because it is applicable under high temperature and magnetic field like TBM. In order to confirm the application of MFAM to the neutron spectrum measurement in the ITER-TBM, we have measured neutron spectra in beryllium and TBM simulating assemblies with a DT neutron source by using MFAM.

\section{Experiment}

\section{ITER-TBM}

Figure 1 shows the design of Japanese TBM, which is inserted in an equatorial port of ITER. The TBM is mainly constructed by using $\mathrm{Li}_{2} \mathrm{TiO}_{3}$ ceramic (lithium- 6 enriched) as a tritium breeder material and beryllium as a neutron multiplier material. Some steel pneumatic tubes are also installed for MFAM.

\section{Experimental Assemblies and DT Neutron Source}

For the MFAM test with DT neutron experiments, we set

*Corresponding Author, E-mail:ochiai.kentaro@jaea.go.jp

(C) Atomic Energy Society of Japan

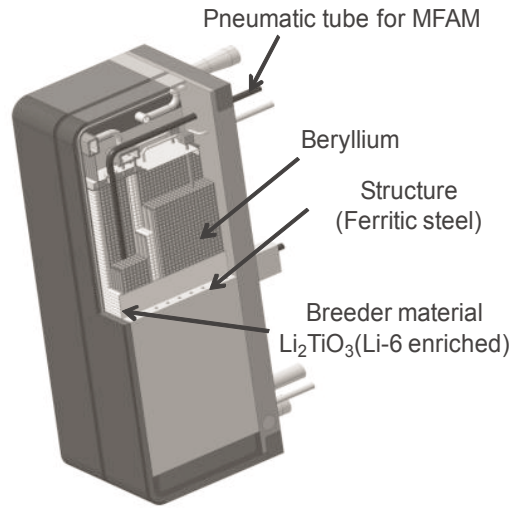

Fig. 1 Design of Japanese TBM

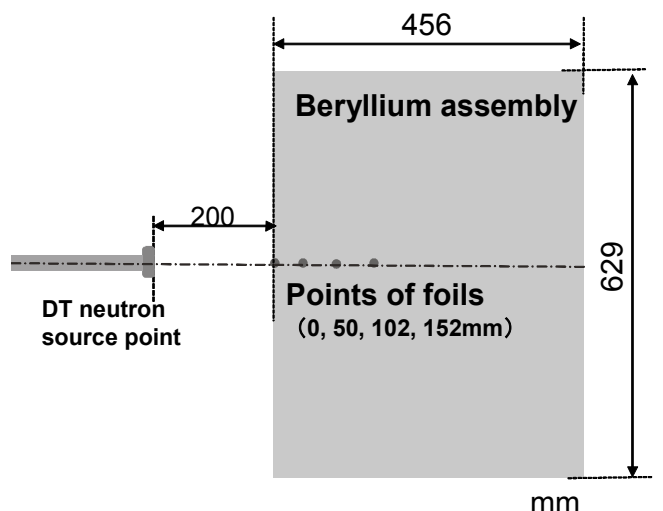

Fig. 2 Cross sectional view of a beryllium experimental assembly

up two assemblies. One is a beryllium assembly and the other is an ITER-TBM simulating assembly. In ITER-TBM, thick beryllium layers are adopted to modify neutron spectra 
in the breeding layers and to increase ${ }^{6} \mathrm{Li}(\mathrm{n}, \mathrm{t})^{4} \mathrm{He}$ reaction rate. Neutron spectra modified with beryllium should be measured accurately. Therefore, we performed a neutron spectrum measurement in a beryllium assembly before doing neutron measurement in the ITER-TBM simulating

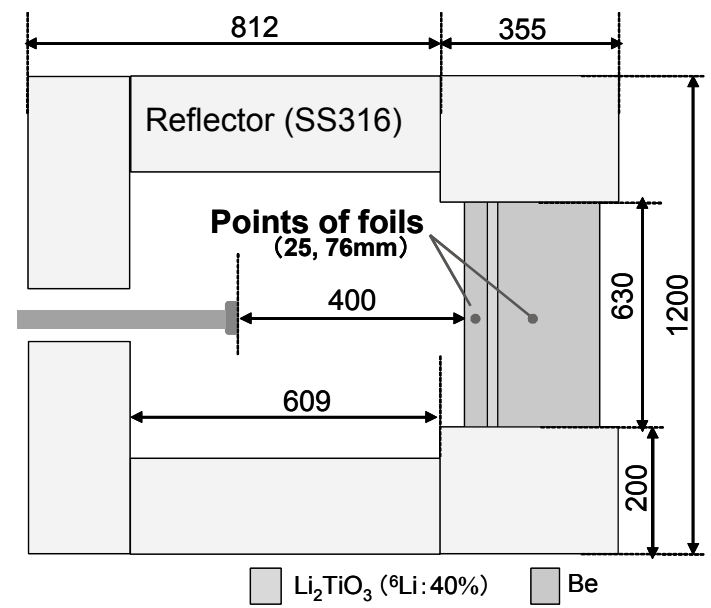

Fig. 3 Cross sectional view of an ITER-TBM simulating assembly

assembly. Figures $\mathbf{2}$ and $\mathbf{3}$ show the cross sectional views of the beryllium assembly and the ITER-TBM simulating assembly, respectively.

The beryllium experimental assembly is a quasi-cylindrical shape $629 \mathrm{~mm}$ in diameter and $457 \mathrm{~mm}$ in thickness, which is set at $200-\mathrm{mm}$ distance from a DT neutron source.

The main part of the ITER-TBM simulating assembly consisted of two beryllium block layers and a $\mathrm{Li}_{2} \mathrm{TiO}_{3}$ ceramics block layer. The thicknesses of the former beryllium block and the latter one were 50.8 and $203.2 \mathrm{~mm}$, respectively. Lithium-6 in the $\mathrm{Li}_{2} \mathrm{TiO}_{3}$ was enriched to 40 atom\% and the thickness of the $\mathrm{Li}_{2} \mathrm{TiO}_{3}$ layer was $24 \mathrm{~mm}$. The simulating assembly was installed to cylindrical hollow stainless steel (SS316) disks. An SS316 cylindrical reflector assembly was also prepared in order to simulate the ITER circumstance.

The DT neutron irradiation experiments were performed at the Fusion Neutronics Source (FNS) facility ${ }^{2)}$ in JAEA. DT neutrons of about $1.5 \times 10^{11}$ neutron/second were generated with $350 \mathrm{keV}$ deuteron beam and a tritiated titanium target $(0.37 \mathrm{TBq})$. A Si-SBD was set up in the beam duct to measure the yields of $3.5 \mathrm{MeV} \alpha$ particle from the DT reaction and total neutron yield was deduced from the $\alpha$ particle yields. The DT neutron irradiation was carried out for about 5 hours.

\section{Multi-Foil Activation Method (MFAM)}

$\mathrm{Al}, \mathrm{Ni}, \mathrm{Zr}, \mathrm{Nb}$, In and $\mathrm{Au}$ foils were used for MFAM. In case of beryllium assembly, the foils were set up at $0,50.8$, 101.6 and $152.4 \mathrm{~mm}$ in depth from the surface. In the simulating ITER-TBM assembly, the positions were 25.4
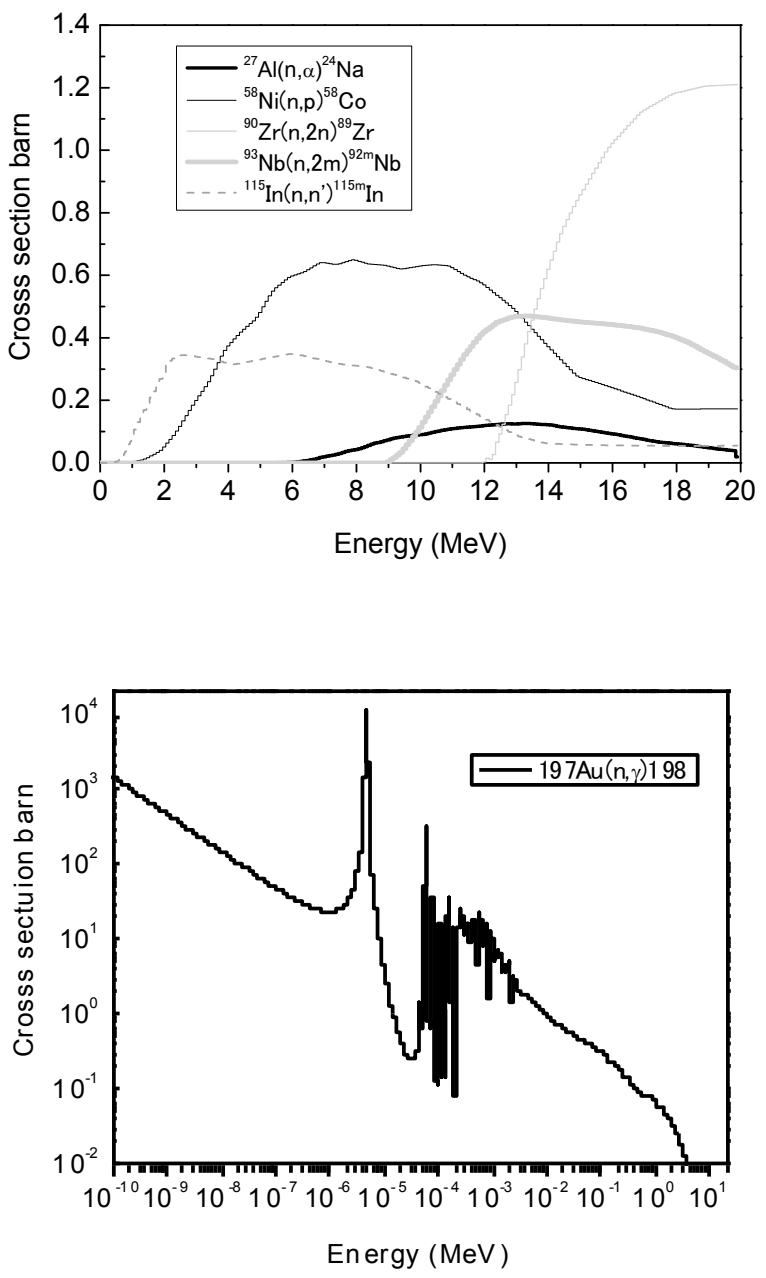

Fig. 4 Activation cross sections of JENDL Dosimetry file 99

and $176 \mathrm{~mm}$.

An unfolding code, NEUPAC ${ }^{3)}$, was used to determine neutron flux spectra. Initial guessed neutron spectra were calculated with a Monte Carlo code $\mathrm{MCNP} 4 \mathrm{C}^{5)}$ and a nuclear data library FENDL-2.1 ${ }^{6}$. JENDL Dosimetry File $99^{4)}$ was adopted as response data for reaction rates in NUPAC. Figure 4 shows activation cross sections of JENDL dosimetry file 99.

As a trial, we also tried to use the rectangular spectrum upto $14.8 \mathrm{MeV}$ and $14.8 \mathrm{MeV}$ peak. However, in case of both case, in order to adjust, we significantly had to turn loose flux limitation level of NEUPAC code and then obtained spectra were not appropriated.

The ${ }^{27} \mathrm{Al}(\mathrm{n}, \alpha){ }^{24} \mathrm{Na},{ }^{93} \mathrm{Nb}(\mathrm{n}, 2 \mathrm{n}){ }^{92 \mathrm{~m}} \mathrm{Nb}$ and ${ }^{90} \mathrm{Zr}(\mathrm{n}, 2 \mathrm{n}){ }^{89} \mathrm{Zr}$ reactions are sensitive to neutron above 5,7 and $12 \mathrm{MeV}$, respectively. ${ }^{15} \mathrm{In}\left(\mathrm{n}, \mathrm{n}^{\prime}\right){ }^{115 \mathrm{~m}} \mathrm{In}$ and ${ }^{58} \mathrm{Ni}(\mathrm{n}, \mathrm{p}){ }^{58} \mathrm{Co}$, which are sensitive to neutron above about $1 \mathrm{MeV}$, were used for the measurement of $\mathrm{MeV}$ neutron spectrum. The ${ }^{196} \mathrm{Au}(\mathrm{n}, \gamma){ }^{197} \mathrm{Au}$ reaction was used for the measurement of slow neutrons below about $10 \mathrm{eV}$. Few activation reactions at the energy range between $1 \mathrm{keV}$ and $300 \mathrm{keV}$ exist.

\section{Reults and Discussion 1. Beryllium Assembly}


Figure 5 shows ratios of initial and derived reaction rates to measured ones each position in the beryllium assembly. The slow neutron spectrum with the ${ }^{196} \mathrm{Au}(\mathrm{n}, \gamma){ }^{197} \mathrm{Au}$ reaction, ${ }^{115} \mathrm{In}\left(\mathrm{n}, \mathrm{n}^{\prime}\right){ }^{115 \mathrm{~m}} \mathrm{In},{ }^{58} \mathrm{Ni}(\mathrm{n}, \mathrm{p}){ }^{58} \mathrm{Co},{ }^{27} \mathrm{Al}(\mathrm{n}, \alpha){ }^{24} \mathrm{Na}$ reactions in most measuring points were to be close to unity. However, initial reaction of ${ }^{58} \mathrm{Ni}(\mathrm{n}, \mathrm{p}){ }^{58} \mathrm{Co}$ at surface point $(0 \mathrm{~mm})$ was not terminated effectively. Since the initial flux near $14 \mathrm{MeV}$ neutron was almost appropriated, the ${ }^{93} \mathrm{Nb}(\mathrm{n}, 2 \mathrm{n})^{92 \mathrm{~m}} \mathrm{Nb}$ and ${ }^{90} \mathrm{Zr}(\mathrm{n}, 2 \mathrm{n}){ }^{89} \mathrm{Zr}$ reactions which contribute to fast neutron

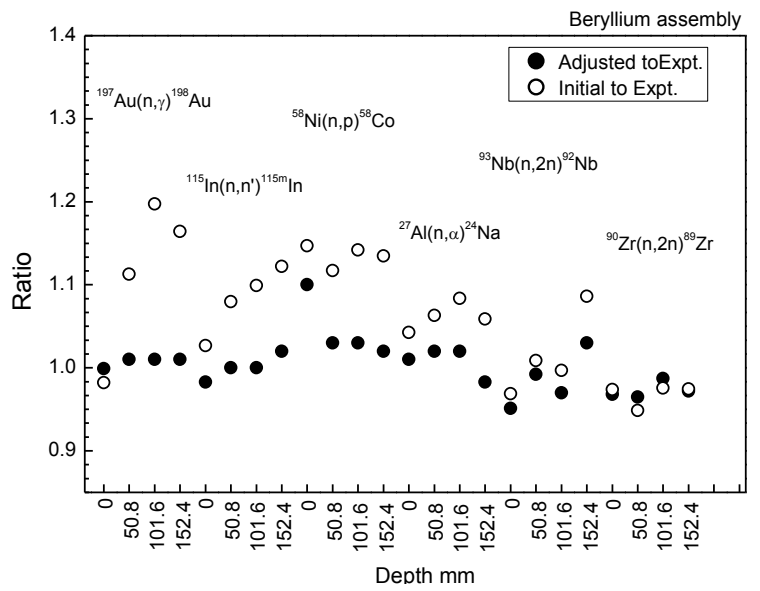

Fig. 5 Ratio of initial and derived reaction rates to measure ones in a beryllium assembly

spectrum were not so effective.

Figure 6 compares initial and adjusted neutron spectra at the depth of $101.6 \mathrm{~mm}$ in beryllium assembly. The spectrum in Figure 6 shows two characteristic changes. One is the flux at the energy range of $1-10 \mathrm{MeV}$ and the other is that for thermal neutron peak and neutrons around $4 \mathrm{eV}$.

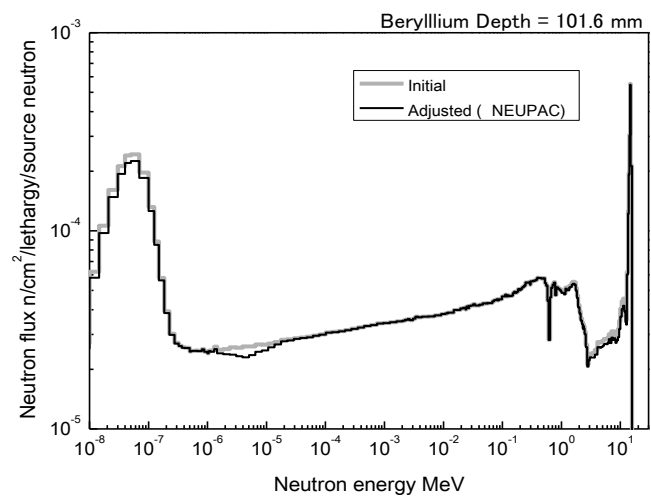

Fig. 6 Initial and adjusted neutron spectra at the depth $101.6 \mathrm{~mm}$ in a beryllium assembly

It is considered that the former is due to inadequate nuclear data. In the past beryllium benchmark experiment ${ }^{7}$, it was pointed out that the calculation with FENDL-2.1 overestimated the neutron flux from 3 to $10 \mathrm{MeV}$, with which the present adjustment is consistent.
As for the unfolding for neutrons below $10 \mathrm{eV}$ in Figure 6, the slow neutron spectrum was adjusted by reflecting the result of the ${ }^{197} \mathrm{Au}(\mathrm{n}, \gamma){ }^{198} \mathrm{Au}$ reaction rate. The cause of underestimation is not clarified yet. However, the tendency is similar to the past beryllium experiment ${ }^{7}$. Not only the thermal neutron peak but also the neutron flux around $4 \mathrm{eV}$ is adjusted into downward, but the latter adjusting comes from the huge resonance peak of $4.9 \mathrm{eV}$ in the ${ }^{197} \mathrm{Au}(\mathrm{n}, \gamma){ }^{198} \mathrm{Au}$ reaction and is not physical because no structure exists around $4 \mathrm{eV}$ in the cross section data of beryllium. For reducing of unphysical adjustment, other reactions, for instance ${ }^{59} \mathrm{Co}(\mathrm{n}, \gamma){ }^{60} \mathrm{Co}$ and $/$ or ${ }^{186} \mathrm{~W}(\mathrm{n}, \gamma){ }^{187} \mathrm{~W}$ reactions should be used. Such reactions have resonances in the different energy range from $4 \mathrm{eV}$ and these will make such local adjustment moderated.

\section{ITER-TBM Simulating Assembly}

Figure 7 also shows ratios of initial and derived reaction

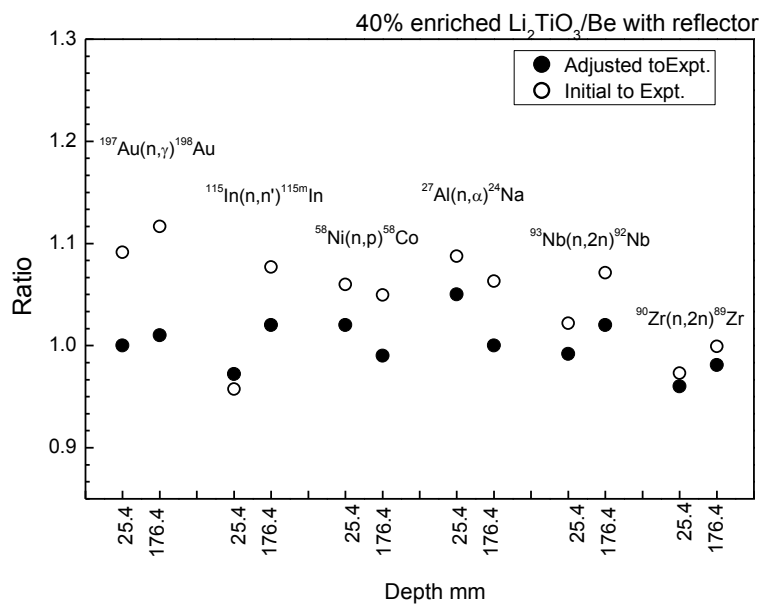

Fig. 7 Ratio of initial and derived reaction rates to measured ones in an ITER-TBM simulating assembly

rates to measured one at each position $(25.4$ and $176.4 \mathrm{~mm}$ in depth). All of derived reaction was close to unity. However, the slow neutron spectrum showed the same

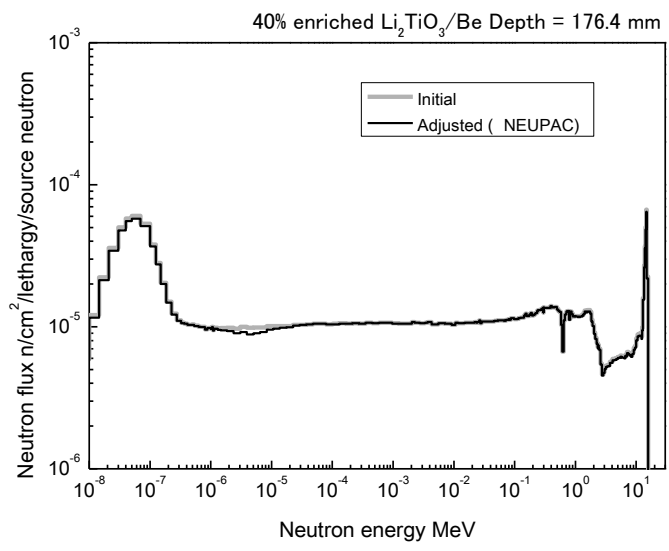

Fig. 8 Initial and adjusted neutron spectra at the depth $176.4 \mathrm{~mm}$ in an ITER-TBM simulating assembly 
phenomenon in the beryllium assembly.

Figure 8 shows initial and adjusted neutron spectra at the depth of $176.4 \mathrm{~mm}$ in the ITER-TBM simulating assembly. Despite the same beryllium region, the neutron spectrum is adjusted without appreciable change unlike the case of the beryllium assembly. Some amount of adjustment appears in the neutron flux below $10 \mathrm{eV}$.

\section{Conclusion}

We have performed the DT neutron irradiation experiment with the beryllium and ITER-TBM simulating assembly in order to examine if the MFAM was to be applicable to the nuclear measurements for the performance test of the ITER-TBM.

The MAFM showed that $\mathrm{MeV}$ neutron spectra in the beryllium assembly appropriately adjustment. However, it was pointed out that a false adjustment for slow neutron spectra in beryllium occurred and it was not sufficient to adjust slow neutron spectrum with only the ${ }^{197} \mathrm{Au}(\mathrm{n}, \gamma){ }^{198} \mathrm{Au}$ reaction.

The adjustment for ITER-TBM simulating assembly was moderated as compared with the beryllium one. But the slow neutron spectra showed the similar tendency in case of the beryllium assembly.

The experiments indicated that MFAM was a prospect to the application of neutron spectrum measurement in ITER-TBM. However, it was also pointed out that some activation reactions for slow neutron measurement were necessary.

\section{Acknowledgment}

The authors would like to thank Messrs. Y. Abe, M. Kawabe, Y. Oginuma, C. Kutsukake and S. Tanaka for their good operation of FNS.

\section{References}

1) H. Tanigawa, T. Hoshino, Y. Kawamura, M. Nakamichi, K. Ochiai, M. Akiba, M. Ando, M. Enoeda, K. Ezato, K. Hayashi, T. Hirose, C. Konno, H. Nakamura, T. Nozawa, H. Ogiwara, Y. Seki, H. Tanigawa, K. Tsuchiya, D. Tsuru T. Yamanishi "R\&D of a $\mathrm{Li}_{2} \mathrm{TiO}_{3}$ pebble bed for a test blanket module in JAEA," Nucl. Fusion 49 No 5 (2009).

2) T. Nakamura, H. Maekawa, Y. Ikeda, Y. Oyama, "A DT neutron source for fusion neutronics yxperiments at the JAERI," Proc. Int. Ion Eng. Congress - ISIAT '83 \& IAPT '83, Kyoto, Japan, Vol. 1, p.567 (1983).

3) M. Nakazawa, A. Sekiguchi, A., Proc. $2^{\text {nd }}$ ASTM-Euratom Symp. on Reactor Dosimetry, NUREG/CP-0004, Vol.3, 1423 (1997).

4) K. Kobayashi, T. Iguchi, S. Iwasaki, T. Aoyama, S. Shimakawa, Y. Ikeda, N. Odano, K. Sakurai, K. Shibata, T. Nakagawa, M. Nakazawa, "JENDL Dosimetry File 99 (JENDL/D-99)," JAERI 1344, Japan Atomic Energy Research Institute, (2002).

5) J.F. Briesmeister (Ed.), "MCNP - a general Monte Carlo n-particle transport code, version 4c," LA-13709-M (2000).

6) D. Lopez Al-dama, A. Trokov, "FENDL-2.1 update of an evaluated nuclear data library for fusion applications," IAEA Report INDC(NDS)-467, International Atomic Energy Agency, (2004).

7) C. Konno, K. Ochiai, M. Wada, S. Sato, "Analyses of fusion integral benchmark experiments at JAEA/FNS with FENDL-2.1 and other recent nuclear data libraries," Fusion Eng. Des., 83, 1774 (2008). 